\title{
ESPAÑA: LOS ACUERDOS DEL ESTADO CON LA SANTA SEDE Y LAS CONFESIONES MINORITARIAS.
}

\author{
JOAQUÍN MANTECÓN*
}

\begin{abstract}
Resumen:
En este artículo se lleva a cabo un somero estudio de los Acuerdos del Reino de España con la Santa Sede y con las Confesiones minoritarias de notorio arraigo, realizando un balance tras sus respectivos períodos de vigencia.

Palabras clave: Acuerdos, concordatos, Santa Sede, Confesiones minoritarias.

Abstract:

Study of the Agreements of the Kingdom of Spain with the Holy See and the minority Confessions deeply rooted in the country, making an evaluation of the experience after their respective period of validity.

Keywords: Agreements, Concordats, Holy See, minority Confessions.

DOI:
\end{abstract}

El próximo año 2017 se cumplirán los veinticinco años -las bodas de plata- de la entrada en vigor de los Acuerdos de cooperación con las Confesiones religiosas minoritarias, y los treinta y ocho de los Acuerdos con la Santa Sede (cuarenta y uno si contamos el denominado «Acuerdo básico», preconstitucional, de 1976). Es pues un momento adecuado para realizar un examen crítico sobre estos instrumentos pacticios para verificar su estado de salud y realizar un diagnóstico. Comenzaremos por los Acuerdos de cooperación y seguiremos con los Acuerdos con la Santa Sede.

\footnotetext{
${ }^{*}$ Catedrático de Derecho Eclesiástico del Estado en la Universidad de Cantabria.
} 
ISSN 0719-7160

Los concordatos, constituyen una de las fuentes normativas más típicas del Derecho Eclesiástico del Estado ${ }^{1}$. Por su génesis, desarrollo y eficacia - de carácter bilateral o pactadosuelen calificarse por la doctrina como fuentes pacticias. Durante mucho tiempo, el concordato fue la única fuente pacticia del Derecho. Sin embargo, modernamente han surgido también Acuerdos con otras Confesiones que carecen de personalidad jurídica internacional. Típicos ejemplos son los Kirchenverträge de los distintos Länder alemanes con las Iglesias evangélicas o el Consistorio israelita ${ }^{2}$, y las Intese italianas con diversas Confesiones minoritarias ${ }^{3}$.

${ }^{1}$ Cfr. J. GotI, Sistema de Derecho Eclesiástico del Estado (Parte general), San Sebastián 1991, p. 256.

${ }^{2}$ Cfr. I. ZABALZA, Los concordatos y contratos Iglesia-Estado en el Derecho eclesiástico alemán, en «Anuario de Derecho Eclesiástico del Estado» 2 (1986), pp. 333-349; A.M. Rouco, Los tratados de las Iglesias protestantes con los Estados, en VV.AA. «La institución concordataria en la actualidad», Salamanca 1971, pp. 105133; A. HollerBACH, El sistema de concordatos y convenios eclesiásticos, en VV.AA. «Constitución y relaciones Iglesia-Estado en la actualidad», Salamanca 1978, pp. 179-192; J. LISTL, Desarrollo y significación de los concordatos y acuerdos eclesiásticos en el Derecho eclesiástico de la República Federal de Alemania, en VV.AA. «Constitución y acuerdos Iglesia-Estado», Madrid 1988, pp. 47-61; J.M. GonZÁLEZ DEL VALLE, Derecho Eclesiástico español, 2a ed., Madrid 1991, pp. 107-113.

${ }^{3}$ Los textos de las Intese pueden verse en S. BerLingò-G. CASUsCELLI, Codice del Diritto Ecclesiastico, 5a ed., Milán 2009. Algunas Intese (en concreto, las celebradas con los Valdenses, las Asambleas de Dios en Italia, la Unión de Iglesias Adventistas del Séptimo Día y la Unión Cristiana Evangélica Bautista de Italia) están publicadas también en la sección de documentación de Anuario de Derecho Eclesiástico del Estado 1 (1985), 2 (1986), 3 (1987) y 9 (1993), respectivamente. Con posterioridad, en 2007, se han firmado intese con la Iglesia ortodoxa, la Iglesia de Jesucristo de los Santos de los Últimos Días, la Iglesia Apostólica en Italia, la Unión budista Italiana y la Unión Hinduista Italiana; y en 2015 con el Instituto Budista Italiano Soka Gakkai. 


\section{Los Acuerdos de cooperación con las Confesiones minorita- rias}

En España, la posibilidad de realizar acuerdos con las Confesiones religiosas distintas de la católica, aparece recogida explícitamente por primera vez en la Ley Orgánica de Libertad Religiosa (LOLR) de 1980.

Existe un acuerdo unánime en la doctrina en atribuir la naturaleza jurídica de tratado internacional a los acuerdos con la Iglesia Católica; en cambio, existen diversas hipótesis sobre la naturaleza de los acuerdos con las Confesiones minoritarias. De hecho, su promulgación en 1992 dio origen a una verdadera eclosión de artículos y monografías doctrinales sobre la materia, como puede verificarse en el aparato crítico de este trabajo.

Como es sabido, la LOLR, estableció en su art. 7.1 la posibilidad de establecer Acuerdos o Convenios con aquellas Iglesias, Comunidades o Confesiones religiosas que, debidamente inscritas en el Registro de Entidades Religiosas (RER) del Ministerio de Justicia, gozaran de un notorio arraigo en España por su ámbito y número de creyentes. Dichos acuerdos, según especifica el mismo artículo, deben ser aprobados mediante Ley de Cortes. Las tres Confesiones que por entonces recibieron el informe favorable sobre su carácter de «notorio arraigo» fueron la Evangélica, la Judía y la Islámica, representadas por la Federación de Entidades Religiosas Evangélicas de España (FEREDE), la Federación de Comunidades Judías de España (FCJE) y la Comisión Islámica de España (CIE), respectivamente.

Todo el mundo concuerda en que material y formalmente, la ley mediante la cual se aprueban los acuerdos es una ley ordinaria, y en este sentido su naturaleza jurídica no plantea ningún problema. Es la naturaleza del acuerdo propiamente dicho, el aspecto que resulta más problemático ${ }^{4}$. En teoría, un acuerdo consiste en la concurrencia de voluntades sobre

4 Cfr. P. LOMBARdíA-J. Fornés, Fuentes del Derecho Eclesiástico español, en VV.AA. «Derecho Eclesiástico del Estado español», 3ạ ed., (coord. R. NAVARRo VAlLs), Pamplona 1993, p. 145. 
algún o algunos temas. Lo convenido compromete a ambas partes por igual según el principio tradicional de estar a lo pactado. Sin embargo, en nuestro caso concreto, para que el acuerdo entre en vigor, no es suficiente con la mera concurrencia de voluntades de las partes; es necesario que una de ellas -el Estado- lo refrende en instancia soberana, de tal manera que tendrá vigencia sólo y en la medida en que aquél así lo considere oportuno. Así pues, ateniéndonos al Derecho positivo, el acuerdo resulta ser un mero presupuesto de la ley mediante la que es aprobado, y que no compromete en absoluto la soberanía del Parlamento ${ }^{5}$. Es decir, se trata de un acto unilateral estatal. Para Llamazares el acuerdo es sencillamente un procedimiento utilizado por el Estado para «detectar y tener en cuenta con más precisión las características especiales de las distintas creencias en orden a regular el derecho de libertad religiosa de sus ciudadanos» ${ }^{6}$. Se trataría, en definitiva, de una manifestación más del fenómeno, cada vez más recurrente en el Estado moderno de que éste, antes de legislar sobre algún aspecto concreto, procura ponerse de acuerdo con los interlocutores sociales afectados (sindicatos, empresarios, categorías profesionales, etc.) ${ }^{7}$. Hoy por hoy, estos acuerdos, en cuanto tales, suelen ser calificados por la mayor parte de los autores como pactos de Derecho público interno ${ }^{8}$, subrayando, por un lado su carácter de acuerdo con un ente de Derecho público, pero proclamando por otro su naturaleza formal normativa de Derecho estatal interno. En esta línea, el Consejo de Estado los ha definido como «convenios de Derecho público, próximos, aunque diferenciados, de los

5 Cfr. D. LlamazAres, Acuerdos del Estado con las Confesiones religiosas (Addenda a la 1a edición de «Derecho Eclesiástico del Estado»), Madrid s.a., p. 39.

6 Ibidem.

${ }^{7}$ Cfr. I.C. IBÁN, El sistema de fuentes del Derecho eclesiástico, en I.C. IBÁN-A. MOTILLA-L. PRIETO «Curso de Derecho Eclesiástico», Madrid 1991, p. 155; P. LOMBARdía, Fuentes..., cit., p. 141. Cfr. también, las observaciones al respecto de J. MARTínez-TORRón, Separatismo y cooperación en los Acuerdos del Estado con las minorías religiosas, Granada 1994, pp. 53-58.

${ }^{8}$ Cfr., pro ómnibus, F.P. Vera URBAnO, Derecho Eclesiástico I, Madrid 1990, p. 284. 
acuerdos con la Santa Sede ${ }^{9}$, expresión ambigua en la que se recoge el sentir doctrinal más extendido, en la que se introduce un elemento perturbador-por lo menos, no clarificador- que es la comparación con los acuerdos de la Iglesia Católica ${ }^{10}$.

El núcleo del problema estriba en determinar la naturaleza y las mutuas relaciones que pueden darse entre los dos actos o momentos en que puede escindirse el tema. Ibán insiste en la importancia de considerar los dos momentos sucesivos en la génesis del acuerdo: la conclusión del acuerdo en sí, y su aprobación parlamentaria ${ }^{11}$.

El acuerdo, una vez firmado por el Ministro de Justicia en nombre del Gobierno, y por los representantes legítimos de las Confesiones, su contenido, por así decir, escapa ya al control de una de las partes -la religiosa-, y entra en la dinámica jurídica encaminada a su aprobación por las Cortes, primero como proyecto de Ley, y finalmente, una vez aprobado, como Ley propiamente dicha. Según Ibán, el acuerdo en cuanto proyecto de Ley, jurídicamente, según el ordenamiento vigente, no es más que eso: un proyecto de ley; pero en cuanto pacto o acuerdo, no es nada ${ }^{12}$.

A mi modo de ver, aunque esta afirmación sea jurídicamente exacta, podría ser matizada. Pienso que resulta defendible la hipótesis de que los acuerdos, en cuanto pactos -y por tanto como una realidad jurídica-, son algo; son un acto norma que obligaría verdaderamente a las partes. El acuerdo, por definición, aparece como un texto con vocación normativa y vinculante para ambas en virtud del principio «pacta sunt servanda»; aunque no revista una precisa categoría formal en el ámbito de nuestro ordenamiento jurídico. Pero

\footnotetext{
${ }^{9}$ Dictamen del Consejo de Estado de 31 de enero de 1991 sobre el proyecto de acuerdo con la FEREDE (citado por I.C. IBÁN, op. cit., p. 157, nota 48).

$10 \mathrm{G}$. SACERDOTI, con referencia a la Intesa con los judíos escribe que «è sicuramente atto pattizio di diritto pubblico esterno, se considerato dal punto di vista del diritto dello Stato» (Lo statuto dell'ebraismo italiano e la sua rilevanza nello Stato, en VV.AA. «Normativa ed organizzazione delle minoranze confessionali in Italia», Turín 1992, p. 128).

${ }^{11}$ Cfr. I.C. IBÁN, op. cit., p. 156.

${ }^{12}$ Ibidem, p. 157.
} 
si la LOLR habla de acuerdos o convenios con las Confesiones, por más que los supedite a la ulterior aprobación formal del legislativo, habrá que entender que lo que pretende establecer con las Confesiones son verdaderos acuerdos o pactos, de los que resulte un empeño mutuo ${ }^{13}$.

Por ello algunos autores pretendían salvar su carácter pacticio, proponiendo que las Cortes aprobaran o rechazaran el acuerdo en bloque, sin actuar la posibilidad real que tiene el Parlamento de entrar en la modificación de su contenido. Esto demostraría la voluntad de las Cámaras de respetar el principio de «stare pactis» ${ }^{14}$. Esta solución no sólo respeta las previsiones legales, sino que, por otro lado, la asemeja a la aprobación -y sólo a este aspecto- de los tratados internacionales, cuya ratificación es autorizada por las Cortes, pero sin posibilidad de modificaciones parciales ${ }^{15}$.

Se podrían pensar otros recursos de cara a otorgar a los acuerdos una naturaleza verdaderamente pacticia. Por ejemplo, incluir una cláusula que impusiera el previo y mutuo acuerdo de las Partes para su eventual modificación o supresión. De hecho, las disposiciones adicionales de los tres acuerdos en vigor van en esta dirección, sin embargo no deja de constituir una mera declaración de buenas intenciones porque todo posible cambio, como explícitamente declara la Adicional Segunda, está sometido a la soberanía del Parlamento, lo que en definitiva coloca a una de las partes en posición de absoluta supremacía.

En otro orden de cosas, hay que hacer notar también el carácter abierto de estos acuerdos, ya que las Iglesias y Comunidades miembros de las Federaciones que pactan con el Estado

${ }^{13}$ Cfr. J. MARTínez-TORRón, Jerarquía y antinomias de las fuentes del nuevo Derecho Eclesiástico español, en «Anuario de Derecho Eclesiástico del Estado» 3 (1987), pp. 146-147; IDEM, Separatismo y cooperación..., cit., p. 111.

${ }^{14}$ Cfr. A. Motilla, Proyectos de Acuerdo entre el Estado y las Federaciones evangélica y judía; primeras valoraciones, en «Revista de Derecho Público»120-121, 1990., p. 596; M.E. OLMOS, Los acuerdos con la FEREDE, $\mathrm{FCl}$ y $\mathrm{ClE}$, en VV.AA. «Acuerdos del Estado Español con los judíos, musulmanes y protestantes», Salamanca 1994, p. 105.

${ }^{15}$ Ibidem. 
pueden dejar de formar parte de aquéllas, y también resulta posible que otras nuevas Iglesias o Comunidades se incorporen con posterioridad. Basta una certificación de la Federación correspondiente, para que la nueva Iglesia o Comunidad -con tal de que figure inscrita en el RER- pueda registrarse como miembro de aquélla, y por tanto, pase a disfrutar de todos los derechos y obligaciones contemplados en el acuerdo.

Ciertamente, los acuerdos con las Confesiones minoritarias de 1992, constituyeron una de las novedades más sobresalientes en el panorama de las fuentes del Derecho Eclesiástico español de la época. Ya lo fueron en el plano estrictamente doctrinal a raíz de la promulgación de la LOLR. La literatura en torno a los acuerdos delineados por su artículo 7 fue, como ya se ha indicado, abundante ${ }^{16}$. Tanto como para que algunas sugerencias doctrinales resultaran acogidas en la formulación de los acuerdos, o bien en el procedimiento que llevó a su aprobación ${ }^{17}$.

\section{Características y contenido de los Acuerdos de cooperación}

¿Qué reflexiones sugiere, a posteriori, su estudio? En primer lugar se tiene la impresión de que se buscó crear un instrumento jurídico sencillo, pero lo suficientemente completo como para desarrollar en paralelo los mismos temas objeto de acuerdos con la Iglesia Católica, de manera que se pusiera en evidencia una cierta voluntad de aplicar el principio de igualdad.

El criterio fue el de reunir en un sólo texto los temas que fueron acordados con la Iglesia Católica en cuatro. Al Acuerdo de Asuntos Jurídicos (AAJ) corresponderían grosso modo los siete primeros artículos (con excepción del 4); al de Asistencia religiosa a las Fuerzas Armadas, corresponden el 4 y el 8; al de Enseñanza y Asuntos Culturales (AEAC) el 10 y el 13

\footnotetext{
${ }^{16}$ Cfr. A. Motilla, Los acuerdos entre el Estado y las Confesiones religiosas en el Derecho español, Barcelona 1985, p. 323.

${ }^{17}$ Cfr. J. FerReR, Los acuerdos con las Confesiones religiosas (Anotaciones y comentarios a una monografía de Agustín Motilla), en «lus Canonicum» 60 (1990), p. 654.
} 
(este último sólo en los acuerdos con la FCJE y CIE); y al de Asuntos Económicos (AAE) el extenso y complejo art. 11.

En cambio, no se contempló en los acuerdos, por ejemplo, la libertad de publicación y comunicación de las autoridades religiosas (aspecto recogido muy genéricamente en el art. 2.d.2 de la LOLR y en el art. II del AAJ); la incidencia de las resoluciones de los tribunales rabínicos o cheránicos en materia matrimonial (art. VI AAJ); la enseñanza de la religión en las Escuelas de Magisterio (art. IV AEAC); la posibilidad de establecer en Universidades estatales centros de estudios superiores teológicos (art. XII AEAC); la exigencia de respeto en los medios de comunicación estatales de los sentimientos religiosos propios (art. XIV $A E A C)$. Pienso que casi todos estos puntos hubieran podido tener cabida en los tres acuerdos. Ignoro las razones que llevaron a no incluirlos.

Los tres textos son muy similares, tanto en su estructura, como en el tratamiento de los temas, aunque existen algunos artículos específicos para los Acuerdos con musulmanes y judíos. Si los ponemos en tres columnas paralelas observaremos que los mismos artículos tratan idénticas materias.

Así, por ejemplo, en el artículo 1, se determina las iglesias o comunidades a las que se aplicará el Acuerdo y la forma en que se incorporan a la respectiva Federación confesional. El artículo 2 define los lugares de culto y establece su régimen jurídico, mientras el artículo 3 define los ministros de culto (o dirigentes religiosos islámicos e imanes en el caso de los musulmanes) y establece el llamado secreto ministerial. El artículo 4 se refiere al servicio militar de los ministros de culto o personas en período de formación para ello. Es de advertir que al haber sido suspendido el servicio militar obligatorio en diciembre de $2001^{18}$. En el artículo 5 se prevé la incorporación de los ministros de culto a la Seguridad Social, asimilados a los trabajadores por cuenta ajena, asumiendo las iglesias y comunidades la

${ }^{18}$ Cfr. Real Decreto 247/2001, de 9 de marzo, por el que se adelanta la suspensión de la prestación del servicio militar al 31 de diciembre de 2001 (BOE de 10 de marzo). 
función del empresario. En el artículo 6 se declara lo que hay que entender por funciones de culto o asistencia religiosa.

En el largo artículo 7 se establecen los efectos civiles del matrimonio celebrado en forma religiosa. El artículo dispone que tendrá efectos civiles cuando el consentimiento matrimonial se preste ante el ministro de culto oficiante, $y$, al menos, dos testigos mayores de edad, y siempre que el matrimonio se celebre antes de que hayan transcurrido seis meses desde la expedición de la certificación civil de capacidad matrimonial. En efecto, para poder contraer en la forma indicada, es necesario que, con anterioridad, los contrayentes promuevan el expediente previo de capacidad ante el Encargado del Registro Civil. De esta manera se asegura la validez de la celebración en lo que se refiere a la ausencia de impedimentos, y se facilita la ulterior inscripción en dicho Registro. Es una solución similar a la adoptada por las Intese italianas. Sin embargo, no se reconoce ninguna eficacia a las decisiones in re matrimoniale de los tribunales cheránicos o rabínicos.

La regulación del matrimonio islámico tiene alguna pequeña pero significativa variante: se puede contraer sin incoar el expediente previo de capacidad matrimonial, y el matrimonio es válido si reúne los requisitos exigidos por el Código civil, pero la inscripción en el Registro civil ya no es automática y requiere la comprobación del cumplimiento de dichos requisitos. ${ }^{19}$

En los artículos 8 y 9 se regula la asistencia religiosa en el seno de las Fuerzas Armadas, mediante un sistema de libre acceso y libre salida, y en los hospitales públicos y centros penitenciarios, mediante un sistema de libre acceso. Los asistentes religiosos son propuestos por las iglesias o comunidades y acreditados por la dirección de los centros respectivos. En el artículo 10, se recoge cuanto se refiere a la enseñanza religiosa en el sistema educativo público y privado concertado (enseñanza optativa a cargo de las Iglesias o Comunidades); los profesores son propuestos por las iglesias o comunidades con la conformidad de la respectiva Federación. También se prevé que las iglesias y comunidades puedan crear

${ }^{19}$ Cfr. Instrucción de 10 de febrero de 1993 de la Dirección General Registros y Notariado, sobre inscripción de determinados matrimonios celebrados en forma religiosa (BOE de 24 de febrero). 
centros educativos de educación primaria y secundaria, y cursos de enseñanza religiosa en las Universidades

En el largo y complejo artículo 11 se establecen los beneficios fiscales y tributarios, tanto para las Federaciones como para sus Iglesias o Comunidades miembros, y para algunas de sus actividades. El principio general es que las entidades religiosas gozan de los beneficios fiscales y tributarios previstos para las entidades sin fin de lucros y las benéficas privadas. En el artículo 12 se contempla la incidencia en el régimen laboral y educativo de los días y fiestas sagrados propios que no coincidan con los establecidos, con carácter general, en el Estatuto de los Trabajadores. El principio es que se reconocen estos festivos propios siempre que exista acuerdo entre las partes. Los alumnos están exentos de asistir a clase y de presentar exámenes en dichos días y, en caso de oposiciones a la Administración pública las pruebas habrán de celebrarse en otra fecha si no existe causa motivada que lo impida. Los artículos 13 y 14 sólo existen en los Acuerdos con judíos y musulmanes. El 13 se refiere a la cooperación del Estado con las respectivas Federaciones de cara a la conservación del patrimonio histórico-artístico de carácter judío o islámico, que en España tiene una variada y rica presencia. Y el 14 regula la protección de las marcas halal y kosher, y el sacrificio ritual de carnes.

\section{Los Acuerdos y el principio de igualdad}

No cabe duda que todas las llamadas de atención por parte de la doctrina en orden a que los acuerdos se concluyeran teniendo presente el principio de igualdad, dieron, como decía antes, un cierto fruto. Si bien, la igualdad conseguida fue valorada de manera muy diversa por parte de los distintos autores.

La preocupación por respetar al máximo el principio de auto-organización de las distintas Confesiones, reflejado en el art. 2.2 de la LOLR ${ }^{20}$, ha llevado a utilizar con la técnica de la

\footnotetext{
${ }^{20}$ Las Intese italianas son mucho más explícitas a este respecto; cfr., por ejemplo, los arts. 2 de los acuerdos con los Valdenses, las Asambleas de Dios y los Adventistas.
} 
remisión a los propios ordenamientos confesionales a la hora de fijar conceptos importantes, como la identificación de los ministros de culto (art. 3) y los lugares de culto (art. 2), las funciones ministeriales (art. 6), las formas matrimoniales (art. 7.1), etc. La ausencia de una presencia institucional de las Confesiones minoritarias en la historia reciente del Derecho patrio, hacía esta definición por demás necesaria. Sin embargo, en algunos casos, y para garantizar una mayor seguridad jurídica el Estado ha exigido que la decisión confesional se acredite mediante certificaciones, o ha exigido autónomamente algún otro tipo de requisito, como el carácter estable de los ministros o lugares de culto.

En segundo lugar los acuerdos sirvieron para fijar concretamente los modos en que el Estado puede cooperar más directamente con las Confesiones, para garantizar que éstas puedan realizar en la práctica el ejercicio -también a nivel colectivo- del derecho de libertad religiosa garantizado por la CE y la LOLR: asistencia y educación religiosa (arts. 8, 9 y 10), descanso semanal y festividades religiosas (art. 12), etc. Dentro de este mismo capítulo de la cooperación entrarían las formas de cooperación económica (art. 11) y la concesión de efectos civiles al matrimonio religioso (art. 7).

En todos estos aspectos se procuró, en la medida de lo posible, buscar una cierta equiparación con lo acordado con la Iglesia Católica ${ }^{21}$, de manera que los acuerdos con la Iglesia Católica han venido a perder el aspecto privilegiario que parecían ostentar hasta el año $1992^{22}$.

A mi parecer, se lograron algunos avances en ese sentido, aunque en algunos puntos muy determinados resultara todavía evidente la desigualdad (problema aparte sería determinar

${ }^{21}$ Cfr. A. Martínez Blanco, Derecho Eclesiástico..., cit., p. 318.

22 No opinó así D. BASTERRA, Acuerdo Estado Español-Federación Evangélica, en ADEE 7, 1991, pp. 587-588; J.A. SOUTO sostuvo una opinión mixta, pues por un lado considera que "gli accordi salvano in parte l'immagine della Chiesa cattolica come confessione particolare e privilegiata, essendo la unica confessione che fino ad allora aveva sottoscritto accordi», y por otro "si mantiene un regime manifestamente diverso tra il sistema pattuito con la Chiesa cattolica e quello pattuito con le confessioni storiche di minoranza» (cfr. Gli Accordi dello Stato spagnolo con le minoranze confessionali tradizionali, en «ll Diritto Ecclesiastico» 1993-3, p. 546). 
si dicha desigualdad es razonable o no). En concreto, la equiparación es prácticamente total en los siguientes aspectos ${ }^{23}$ : protección de los lugares de culto (art. 2.2,3 y 4) e inviolabilidad de archivos (art. 2.2 ClE); exención a los ministros de culto de la obligación de revelar lo que conozcan por razón del ministerio (art. 3.2); seguridad social del clero (art. 5); designación de profesores y determinación del material docente (art. 10.2 y 3); enseñanza religiosa en la Universidad (art.10.5); posibilidad de crear centros docentes y seminarios (art. 10.5 y 6); posibilidad de organizar colectas y recabar ofrendas y cuanto se refiere a exenciones tributarias y ventajas fiscales (art. 11), salvo en lo que concierne al sistema de financiación con los provenientes del porcentaje del IRPF -asignación tributaria-, que se aplica sólo a los católicos.

Sin embargo existen materias en que la regulación no es equiparable. Así, el modelo elegido para proporcionar asistencia religiosa en el seno de las Fuerzas Armadas, hospitales y centros penitenciarios, que es el denominado por la doctrina "de libre acceso», frente al concordado con la Confesión mayoritaria, que prevé el establecimiento de capellanías permanentes financiadas por el Estado. Lo que se puede explicar razonablemente por el limitado número de fieles de estas Confesiones, y su dispersión, aunque, en algunos casos pueda responder a una opción concreta de la Confesión que, por un lado ve suficientemente asegurada la debida asistencia a sus fieles, y al mismo tiempo se coloca en una posición de menor dependencia del Estado. Pero, en la práctica, hoy en día, las Confesiones reclaman un régimen diferente tendencialmente más parecido al utilizado con la Iglesia Católica.

También resultaba diverso el modelo de impartición de la enseñanza religiosa, aunque en este último supuesto, con posterioridad, se firmaron unos Convenios con las Federaciones evangélica e islámica que, en la práctica, cambiaban el sistema e instauraban uno muy parecido al establecido con la Iglesia Católica, de tal manera que el Estado se hace cargo de

${ }^{23}$ El artículo de D. BASTERRA citado, y con referencia al sólo acuerdo con la FEREDE, va realizando la comparación con los acuerdos de la Iglesia Católica, y valorando lo que a su juicio supone una quiebra de la igualdad. 
los gastos derivados de la enseñanza siempre que, en un centro educativo se reúnan, al menos, 10 alumnos que la hayan solicitado. ${ }^{24}$ Hoy en día, tras la promulgación de la Ley Orgánica de Educación y la de Calidad de la Educación, el estatutos de la asignatura y de los profesores de religión es idéntica, salvo en la equiparación de la asignatura como fundamental.

Por lo que se refiere a la asignación tributaria los evangélicos la rechazaron por razones intraconfesionales, mientras que, en el caso de los judíos, el rechazo pudo basarse en el recuerdo de la persecución nazi, que se sirvió de los elencos del impuesto eclesiástico vigente en Alemania para identificar a los hebreos. En el caso de los musulmanes la solicitaron y se les denegó, por considerar que la asignación tributaria tenía un carácter provisional. No obstante, a día de hoy, tanto evangélicos como musulmanes - no así los judíos- aspiran a que les conceda la asignación tributaria.

A pesar de lo dicho anteriormente, en algún aspecto concreto, como es el caso de las parcelas reservadas a judíos y musulmanes en los cementerios municipales, la solución adoptada parece privilegiar a estas Confesiones, frente al Derecho común, que es el aplicable a la Iglesia Católica.

Por otra parte, ya he adelantado la duda de que, a veces, las desigualdades observadas responden más a una opción concreta de la confesión afectada, que a cicatería por parte del Estado. Por ejemplo, con la finalidad de procurarse una menor dependencia del Estado (modelo asistencial «de libre acceso» ${ }^{25}$ ), o simplemente por condicionamientos sociológicos, como por ejemplo el número relativamente bajo de fieles. En otros casos, pienso, no habría inconveniente en aplicar a estas Confesiones los puntos no incluidos en los acuerdos que, sin embargo, sí aparecen en los de la Iglesia Católica.

${ }^{24} \mathrm{Cfr}$. Convenios sobre designación y régimen económico de los profesores de enseñanza religiosa islámica y evangélica en los Centros docentes públicos de Educación Primaria y Secundaria, de 12 de marzo de 1996, (BOE de 3 y 4 de mayo, respectivamente).

${ }^{25}$ Es el sistema adoptado por todas las Confesiones minoritarias en Italia. 
El que el número de artículos de estos acuerdos sea llamativamente menor (12-14) y toque prácticamente las mismas materias que los acuerdos con la Iglesia Católica (4 acuerdos ${ }^{26}$, con un total de 40 artículos, sin contar anexos y protocolos adjuntos) se explica, a mi juicio, por el hecho, indudable, de la menor complejidad organizativa de estas Confesiones y la menor implantación social, si las comparamos con la Iglesia Católica.

Por lo que se refiere a la objeción que realizó Ibán sobre la sorprendente coincidencia entre acuerdos firmados con tres Confesiones distintas ${ }^{27}$, hay que reconocer el interés del Ministerio de Justicia por dar a los acuerdos un perfil determinado (por intereses, me imagino, de pura practicidad y economía normativa), como se deduce de algunas observaciones de Basterra, miembro de la Comisión que llevó a cabo las negociaciones sobre el anteproyecto o pre-acuerdo con la FEREDE ${ }^{28}$. Motilla subrayó también -y critica- «la aplicación de criterios standard en la regulación de las instituciones confesionales de religiones tan distintas en su conformación histórica, hábitos y creencias», lo que según este autor "defrauda, de

\footnotetext{
${ }^{26}$ Si excluimos el de 5 de abril de 1962, ya citado, sobre efectos civiles de los estudios realizados en Universidades de la Iglesia y el de 28 de julio de 1976. J.M. GonZÁLEZ DEL VALLE considera también como vigente el de 24 de junio de 1867, sobre capellanías colativas y pías fundaciones (cfr. Derecho Eclesiástico..., cit., pp. 128-129). Para el texto de este Convenio-Ley cfr. VV.AA., (coord. J.M. González del Valle), Compilación de Derecho Eclesiástico Español (1816-1986), Madrid 1986, pp. 35-39. Sin embargo, J.M. VÁzQuez GARCíA-PEÑUELA, defiende su no vigencia (cfr. Las capellanías colativo-familiares (régimen legal vigente), Pamplona 1992, pp. 212 y ss.).

${ }^{27}$ Cfr. I.C. IBÁN, Normativa en el Derecho Eclesiástico del Estado, ponencia en el Workshop sobre Derecho Eclesiástico del Estado, Oñate 26-28 de mayo de 1993, (pro manuscripto), p. 23.

${ }^{28}$ A propósito del art. 8 del Anteproyecto escribe que «fue reducido a una cuarta parte sin que tal reducción se efectuase en la Comisión negociadora ni contase con la aprobación de la misma» (op. cit., p. 587, nota 18). Este hecho contrasta fuertemente con la tajante expresión de la exposición de motivos de los tres acuerdos en la que se asegura que «se ha procurado siempre tener el más escrupuloso respeto a la voluntad negociadora de los interlocutores religiosos...».
} 
momento, las expectativas de configurar los acuerdos del art. 7 como instrumentos que atienden a las singularidades de cada confesión ${ }^{29}$.

El caso de la FEREDE, en que se integran Iglesias tan sumamente diversas como pueden ser los adventistas del séptimo día, los luteranos, los presbiterianos, los pentecostales y carismáticos, etc., no facilita precisamente que el acuerdo responda a las necesidades específicas de cada confesión, transformándolo más bien en un «acuerdo marco», o en una especie de «pacto abierto».

Sin embargo, también se puede defender que los intereses de las distintas Confesiones de cara a conseguir las facilitaciones que les permitan realizar su misión religiosa en el seno de una sociedad plural y democrática, son muy parecidos. Y por tanto, es lógico, que los acuerdos de cooperación resulten también parecidos en cuanto a los temas objeto de pacto y en cuanto a los modos concretos que se articulen para conseguir los objetivos propuestos, si no se quiere incurrir en el peligro de lesionar el principio de igualdad o de intervenir indebidamente en decisiones que corresponden exclusivamente a las propias Confesiones.

Por otro lado, hay que subrayar algún aspecto concreto que parece privilegiar a estas Confesiones, frente al Derecho común, y frente a la Iglesia Católica, como es el caso de las parcelas reservadas a judíos y musulmanes en los cementerios municipales (art. 2.6 FCJE y $\mathrm{CIE})$.

En resumidas cuentas, los acuerdos, en la medida en que existen, no dejan de constituir una realidad positiva. Ahora bien, dejando de lado las posibles críticas sobre el nivel de igualdad conseguido en relación con los acuerdos con la Iglesia Católica (lo que constituye un capítulo a se), da la impresión de que a la Administración le faltó imaginación (o quizás, y más verosímilmente, generosidad), y a las Confesiones una mayor audacia en sus planteamientos, ya que el resultado final son unos acuerdos prácticamente indiferenciados y

${ }^{29}$ Cfr. A. Motilla, Proyectos..., cit., p. 621. 
con una normativa que innova muy poco, o nada, sobre la ya existente, como puede comprobarse si se consulta la legislación en vigor sobre estos mismos temas previa a los acuerdos $^{30}$. En realidad, a veces, se tiene la impresión de que la Administración lo único que pretendió fue firmar unos acuerdos que sirvieran para dar una especie de satisfacción moral, con más efectos psicológicos que jurídicos, a unas Confesiones que habían estado claramente discriminadas en el pasado.

\section{Los Acuerdos en cuanto fuentes pacticias}

En cuanto a su aspecto pacticio, pienso que hay que subrayar el peso de la doctrina, que mayoritariamente aboga por que, con independencia de su carácter normativo formal, se aplique en el espíritu del principio «pacta sunt servanda». Desde un punto de vista teórico, el instrumento ideal sería una Ley Orgánica, en la medida en que se considere que los acuerdos suponen el desarrollo del derecho fundamental de libertad religiosa en su vertiente colectiva. Sin embargo, vemos difícil que se pudiera adoptar esta solución, puesto que tanto la doctrina como el Tribunal Constitucional abogan por una interpretación estricta del art. 81 de la $C E^{31}$. Por tanto, aunque pudiera parecer que la utilización de una ley ordinaria supone un cierto rebajamiento en cuanto a la categoría de la norma adoptada ${ }^{32}$, hoy por hoy, esta es la única posibilidad viable. Lo que sí sería deseable y posible es que, si se llegaran a firmar nuevos Acuerdos, la ley de aprobación incluyera una cláusula en la que

${ }^{30}$ Cfr. J.A. Souto, Gli Accordi... cit., p. 546; M. TEDESCHI, op. cit., p. 598.

31 Cfr. F. BALAguer, Fuentes del Derecho; ordenamiento general del Estado y ordenamientos autonómicos, Madrid 1992, pp. 69-70; E. GARCíA DE EnTERRíA-T.R. FernÁNDEZ, op. cit., pp. 126-128; Sentencias del Tribunal Constitucional 6/1982, de 22 de febrero y 76/1983, de 5 de agosto.

32 Para un amplio sector de la doctrina, la Ley Orgánica posee un rango normativo superior al de la mera ley, sin embargo GARCíA DE ENTERRÍA y T.R. FERNÁNDEZ, mantienen que no existe tal diferencia de rango; si una ley ordinaria no puede modificar o derogar una Ley Orgánica, no es tanto porque su rango sea inferior, sino por la reserva de materias que efectúa el art. 81 de la Constitución Española (cfr. op. cit., pp. 121-123); en términos parecidos se expresa J. MARTínEZ-TORRón, Jerarquía y antinomias..., cit., pp. 136-137. 
se determinara que cualquier modificación o cambio del contenido del acuerdo, requiriera el consenso de la otra parte ${ }^{33}$. De esta manera se salvaría decididamente la naturaleza pacticia del acuerdo. No me parece que sea una hipótesis descabellada o desorbitada, si tenemos en cuenta que en la Adicional segunda se admite la posibilidad de denuncia del acuerdo, eventualidad ciertamente peculiar desde el punto de vista jurídico en una Ley de Cortes, pero no más peculiar -me parece-que la que propongo.

\section{Los Acuerdos de cooperación tras veinticinco años de vigen- cia}

El tiempo transcurrido ha permitido valorar lo que los Acuerdos han supuesto para las Confesiones que los firmaron, así como detectar e identificar aspectos que convendría retocar o reformar (sin excluir la posibilidad de incorporar aspectos nuevos no recogidos en los textos vigentes).

Ya los diez años de su entrada en vigor -el año 2002- la Comisión Asesora de Libertad (CALR) religiosa organizó un seminario interno para discutir y valorar su existencia y oportunidad. Tomaron parte en él expertos todos los miembros de la CALR, aunque los ponentes pertenecían al tercio de expertos. Los representantes de las Confesiones intervinieron también de manera sistemática. Los resultados de este seminario se publicaron en un volumen el año $2003^{34}$.

El Prof. Motilla, abordó directamente los aspectos que, en su opinión, habían de ser reformados, que afectaban a prácticamente todos los artículos de los Acuerdos, pero sin introducir grandes cambios, sino únicamente pequeños retoques en aras de conseguir una ma-

33 Es la tesis de A. Motilla (cfr. Los Acuerdos..., cit., p. 343).

${ }^{34}$ VV.AA. Los Acuerdos con las Confesiones minoritarias. Diez años de vigencia, Ministerio de Justicia, Madrid, 2003, 372 págs. 
yor igualdad con el régimen de la Iglesia Católica, mejorar la seguridad jurídica, o de facilitar la ejecución de lo pactado ${ }^{35}$. Apuntaba el autor, por ejemplo, la conveniencia de que los lugares de culto y los ministros de culto pudieran anotarse o inscribirse en el RER; de exigir el certificado de capacidad matrimonial para celebrar el matrimonio islámico; y en temas como la asistencia religiosa y el régimen fiscal y tributario se pedía una mayor igualdad con el régimen de la Iglesia Católica.

De forma parecida se manifestaba el Profesor Martínez Torrón ${ }^{36}$, si bien hace particular hincapié en reconocer como objeción de conciencia el secreto ministerial de los ministros de culto, el derecho al descanso sabático o las prescripciones religiosas sobre alimentos. Se muestra también partidario de extender el sistema de asignación tributaria a las tres Confesiones. Los Profesores Vázquez García-Peñuela y Martín-Retortillo, realizan, por su parte, unas aportaciones más genéricas sobre los propios Acuerdos, sin entrar en muchos detalles sobre aspectos concretos ${ }^{37}$.

Si, como hemos visto, ya en 2002 existía una opinión mayoritaria partidaria de actualizar los Acuerdos, en la actualidad esa misma opinión no sólo sigue existiendo sino que, quizás, se ha reforzado ${ }^{38}$. Si bien algunas de las sugeridas reformas de los Acuerdos se han llevado a cabo mediante la legislación unilateral del Estado. Así ha sucedido, por ejemplo, en el caso de la anotación en el RER de los lugares y ministros de culto, que ha sido adoptada

35 A. MotILLA, La reforma de los Acuerdos de cooperación con las Federaciones evangélica, judía y musulmana, en VV.AA. «Los Acuerdos...» cit., págs. 19-55.

36 J. Martínez Torrón, Diez años después. Sugerencias sobre una posible revisión de los Acuerdos de 1992 con las Federaciones evangélica, israelita e islámica, en VV.AA. «Los Acuerdos...» cit., pp. 87-140.

37 J.M. VÁZQUEZ Ga PEÑUELA, El futuro de los Acuerdos y otros ámbitos de cooperación entre el Estado y las Confesiones; L. MARTín-RetORTILlo, Reflexiones sobre los Acuerdos de cooperación del Estado con las Federaciones evangélica, judía y musulmana, en los diez años de su vigencia; ambas en VV.AA. «Los Acuerdos...» cit., págs. 157-191, y 239-275, respectivamente.

38 Cfr. M. Blázquez, Cooperación con la FEREDE, propuestas de reforma, en VV.AA. (R. García y M. Gonzalez Coords.), «Aplicación y desarrollo del Acuerdo entre el Estado y la FEREDE», Madrid 2008, pp. 69-97. 
por el nuevo Real Decreto sobre el Registro de Entidades Religiosas, del año 2015 ${ }^{39}$. O, como sostiene la doctrina, la necesidad de obtener el certificado de capacidad matrimonio antes de proceder a la celebración del matrimonio islámico ${ }^{40}$. Lo mismo ha sucedido con la necesidad de que los ministros que celebran un matrimonio sean acreditados, cosa que ha hecho la nueva Ley de Jurisdicción Voluntaria de $2015^{41}$. Por otro lado, la no exigencia de licencias especiales para la apertura de lugares de culto ha sido instrumentada por la Ley de racionalización y sostenibilidad de la administración local, de $2013^{42}$.

Por otra parte, algunos aspectos de su contenido ha sido desarrollado mediante convenios o normativa unilateral del Estado. Así por ejemplo, cabe citar los Convenios sobre designación y régimen económico de las personas encargadas de la enseñanza religiosa evangélica e islámica ${ }^{43}$, de 1996; o el Convenio firmado con la Comisión Islámica de España para la financiación de los gastos del desarrollo de la asistencia religiosa en los establecimientos penitenciarios, de 2007. En el plano unilateral cabe reseñar la fijación del estatuto jurídico de la asignatura de religión, y el régimen de los profesores de religión, realizada por la Ley

${ }^{39}$ Cfr. Arts. 16 y 17 del Real Decreto 594/2015, de 3 de julio, por el que se regula el Registro de Entidades Religiosas (BOE de 1 de agosto).

${ }^{40}$ M. LEAL AdORnA, Los matrimonios religiosos no canónicos a la luz de la nueva Ley de Jurisdicción Voluntaria, en «Revista General de Derecho Canónico y Derecho Eclesiástico del Estado», 41 (2016).

${ }^{41}$ Cfr. Disposiciones finales, quinta, sexta y séptima de la Ley 15/2015, de 2 de julio de Jurisdicción Voluntaria (BOE de 3 de julio).

${ }^{42}$ Cfr. Disposición adicional decimoséptima de la Ley 27/2013, de 27 de diciembre, de racionalización y sostenibilidad de la administración local (BOE de 30 de diciembre).

${ }^{43}$ Resolución de 23 de abril de 1996, de la Subsecretaría de Presidencia, por la que se dispone la publicación del Acuerdo del Consejo de Ministros, de 1 de marzo de 1996, y los Convenios sobre designación y régimen económico de las personas encargadas de la enseñanza religiosa evangélica e islámica, en los centros docentes públicos de educación primera y secundaria (BOE de 3 y 4 de mayo). 
Orgánica de Educación de $2006^{44}$ y un Real Decreto de $2007^{45}$, que desarrolla este punto, así como por la Ley de Mejora de la Calidad Educativa de 201346. También cabe mencionar la promulgación de un Real Decreto de desarrollo de los Acuerdos de Cooperación con la FEREDE, FCJE y CIE, de 2006, en el ámbito de la asistencia religiosa penitenciaria ${ }^{47}$. Por su parte FEREDE ha firmado un Convenio de desarrollo de este Real Decreto en 2015. Finalmente, entre 2014 y 2015 se han firmado sendos Convenios con FEREDE, FCJE y CIE para garantizar la asistencia religiosa en los Centros de Internamiento de Extranjeros.

Por último, aunque no se trate de un desarrollo de los Acuerdos, cabe señalar la creación de la fundación «Pluralismo y Convivencia» el año 2004. Se trata de una fundación del sector público estatal, residenciada en el Ministerio de Justicia, cuya finalidad es sufragar iniciativas culturales, educativas, de integración social y de fortalecimiento institucional de las Confesiones de notorio arraigo, excluyendo las actividades directamente religiosas ${ }^{48}$. Las sucesivas Leyes de Presupuestos Generales del Estado suelen incluir una partida con esta finalidad. Se trata de una subvención directa del Estado -no prevista en los Acuerdosque ha sido muy favorablemente recibida por las Confesiones concernidas.

${ }^{44}$ Cfr. Disposición adicional tercera de la Ley Orgánica 2/2006, de 3 de mayo, de Educación (BOE de 4 de mayo).

45 Real Decreto 696/2007, de 1 de junio, por el que se regula la relación laboral de los profesores de religión prevista en la disposición adicional tercera de la Ley Orgánica 2/2006, de 3 de mayo, de Educación (BOE de 9 de junio).

${ }^{46}$ Cfr. Disposiciones adicionales segunda y tercera de la Ley Orgánica 8/2013, de 9 de diciembre, para la mejora de la calidad educativa (BOE de 10 de diciembre).

${ }^{47}$ Real Decreto 710/2006, de 9 de junio, de desarrollo de los Acuerdos de Cooperación firmados por el Estado con la Federación de Entidades Religiosas Evangélicas de España, la Federación de Comunidades Judías de España y la Comisión Islámica de España, en el ámbito de la asistencia religiosa penitenciaria (BOE de 10 de junio)

48 Vid. M.J. CIÁURRIZ LABIANO, La Fundación Pluralismo y Convivencia, en VV.AA. "Aspectos del régimen económico y patrimonial de las confesiones religiosas», Granada 2008, pp. 105-122. 
Sin embargo, siguen pendientes de resolución algunos grandes temas, como la extensión de la asignación tributaria, o la reforma del sistema de asistencia religiosa. Ahora bien, existe la sensación generalizada de que, en estos momentos no existe voluntad política en el Ejecutivo de revisar o reformar los Acuerdos vigentes, por lo que todo hace prever que los cambios -si se adoptan - tendrán lugar mediante la promulgación de normas unilaterales o convenios de ejecución o desarrollo, como por otra parte ha sucedido hasta ahora.

\section{Los Acuerdos con la Santa Sede}

En España, durante la época contemporánea, y con la excepción del breve período republicano (1931-1939), las relaciones con la Iglesia se rigieron por los Concordatos de 1753, 1851 y 1953. El recurso a este instrumento jurídico se justificaba en la necesidad de regular las tradicionalmente denominadas cuestiones mixtas por las dos Potestades con competencias y legitimidad para ello: el Rey o Jefe del Estado, como cabeza y representación de la Nación, y el Papa, como cabeza de la Iglesia Católica.

Los acuerdos con la Santa Sede, que han venido a sustituir al viejo Concordato de 1953, actualmente vigentes en España son los firmados el 28 de julio de 1976 y el 3 de enero de 1979. El procedimiento seguido para su aprobación fue el previsto en la Constitución para los acuerdos internacionales, es decir, el indicado en el art. 94. Por tanto, su posición en la 
jerarquía de normas será el reservado para los tratados ${ }^{49}$ y así lo han reconocido expresamente el Tribunal Constitucional y el Tribunal Supremo ${ }^{50}$. Igualmente, para resolver la posible colisión con otras normas del ordenamiento habrá que recurrir a los principios y reglas generales de interpretación de tratados. Sus disposiciones sólo pueden ser derogadas, modificadas o suspendidas en la forma prevista en los propios tratados o de acuerdo con las normas generales del Derecho internacional en los términos establecidos por el Convenio de Viena sobre el Derecho de los Tratados, de 23 mayo de $1969^{51}$.

\section{El Acuerdo «básico» de 1976}

Recién terminado el régimen del General Franco, y en pleno proceso de transición a la democracia, en 1976, se firmó un Acuerdo, denominado básico por la doctrina, que viene

\footnotetext{
49 Propiamente hablando las normas de un tratado tienen un rango normativo igual al de las leyes; lo que sucede es que su génesis, interpretación y eventual modificación queda sometida a un procedimiento peculiar, tal como establece la Constitución Española (cfr. E. GARCía de EnTERRÍA-T.R. FERnándeZ, Curso de Derecho Administrativo, vol. I, 6a ed., Madrid 1993, p. 142). En el mismo sentido J. PUENTE EGIDO, Los acuerdos entre España y la Santa Sede dentro del sistema constitucional español: su valor como tratados internacionales, en VV.AA. «Constitución y acuerdos Iglesia-Estado», Madrid 1988, p. 21; en contra J. MARTínEZ-TORRón, Jerarquía y antinomias... cit., p. 141.

50 «No podemos menos de constatar que este Acuerdo del Estado Español y la Santa sede tiene rango de tratado internacional y, por tanto, como aprecia el Fiscal, se inserta en la clasificación del artículo 94 de la Constitución Española, sin que respecto a él se hayan, institucionalmente, denunciado, estipulaciones contrarias a la propia Constitución, y, una vez publicado oficialmente el Tratado, forma parte del ordenamiento interno» (Fundamento Jurídico 5은 Sentencia del Tribunal Constitucional 66/1982, de 12 de noviembre; cfr. R. RodríGuez Chacón, El factor religioso ante el Tribunal Constitucional, Madrid 1992, p. 54). Cfr. también Sentencias del Tribunal Supremo de 12 de diciembre de 1980 (Sala 3a) y de 2 de diciembre de 1981 (Sala 3a) en A.C. Alvarez CortinA, El Derecho Eclesiástico español en la jurisprudencia postconstitucional, Madrid 1991, p. 27.

${ }^{51}$ Ratificado por España el 2 de mayo de 1972.
} 
a ser la piedra miliar que marca el nuevo carácter de las relaciones Iglesia-Estado en España. En este Acuerdo, el Rey renunciaba al privilegio de presentación de obispos, penúltima institución de tipo regalista que permanecía en vigor en nuestro ordenamiento; y la Iglesia, por su parte, renunciaba al tradicional privilegio del fuero, por el que ningún clérigo o religioso podía ser juzgado por la justicia ordinaria sin la aquiescencia de la correspondiente autoridad eclesiástica. Pero su verdadera importancia radica en su introducción, en la que se exponen los nuevos principios que habrían de inspirar las relaciones entre España y la Iglesia Católica.

Allí se reconocen los grandes cambios operados en la realidad social y política de nuestro país, así como en la doctrina de la Iglesia sobre la libertad religiosa y las relaciones IglesiaEstado formulada por el Concilio Vaticano II, que postulan una nueva forma de relacionarse entre ambos. Así, por ejemplo, se establecen como criterios rectores de esa nueva relación, la mutua independencia y la sana colaboración, el reconocimiento de la libertad religiosa como derecho de la persona, y de la libertad de la Iglesia para desarrollar su misión en el seno de la sociedad. Por último ambas Partes consideraban necesario ir sustituyendo mediante Acuerdos parciales y sectoriales el obsoleto Concordato de 1953.

Si bien la superación del Concordato de 1953 fue recibida con general satisfacción por todo el mundo, en muchos ambientes -incluso católicos- se manifestaba una cierta perplejidad por la elección de un sistema de Acuerdos concordatarios como forma de regular las mutuas relaciones. Ciertamente la institución concordataria no pasaba por su mejor momento histórico. Sin embargo, la experiencia posterior ha mostrado la eficacia de este instrumento jurídico, como demuestra la firma de más de 30 Acuerdos o Convenios, incluso con países tan ajenos a la tradición católica como pueden ser Kazajstán, Estonia o Israel. ${ }^{52}$

52 Con posterioridad a la conclusión de los Acuerdos con España, la Santa Sede ha firmado numerosos Acuerdos o Instrumentos de carácter concordatario (vid. J.T. MARTín DE AGAR, Raccolta di Concordati 19501999, Roma 2000, con su apéndice I Concordati del 2000, Roma 2001). Con posterioridad se ha firmado algunos más. Solamente en Europa existen 24 países concordatarios (sin contar los Acuerdos con 16 Länder alemanes o con 6 cantones suizos), más 1 firmado con la propia Unión Europea. A éstos habría que sumar 


\section{Los Acuerdos de 1979}

El 29 de diciembre de 1978 se promulgó la Constitución, aprobada previamente por referéndum de la nación con una aplastante mayoría. Cinco días después, el 3 de enero de 1979, se firmaron cuatro Acuerdos con la Santa Sede. Autorizada su ratificación por el Congreso y el Senado el 13 de septiembre y el 30 de octubre, respectivamente, fueron ratificados por el Rey el 4 de diciembre, y el 15 del mismo mes se publicaron en el Boletín Oficial del Estado (BOE), pasando a formar parte de nuestro derecho interno.

Algunos autores hicieron notar, en su momento, que estos Acuerdos, aunque inmediatamente posteriores a la Constitución, fueron negociados antes de su promulgación. Esta circunstancia cronológica era suficiente para que pusieran en duda su adecuación a los nuevos principios constitucionales. ${ }^{53}$ La verdad es que quienes los negociaron -así lo ha manifestado alguno expresamente- conocían perfectamente los trabajos de los constituyentes $y$, ciertamente, los tuvieron en cuenta. ${ }^{54}$

De hecho, el Tribunal Constitucional, hasta el momento, no sólo no ha declarado la inconstitucionalidad de punto alguno, sino que ha manifestado que pueden y deben ser interpretados de conformidad con la Constitución. ${ }^{55}$ Sin embargo, el Tribunal Superior de Justicia

los 11 Acuerdos firmados con países iberoamericanos, otros 11 africanos, y 8 asiáticos. En total existen 55 países concordatarios y 220 acuerdos firmados. Y muchos de ellos han sido ratificados en los 10 últimos años. Se trata, por tanto, de un fenómeno perfectamente actual y universal (Vid. R. MinNERATH, L'Église catholique face aux États. Deux siècles de pratique concordataire (1801-2010), París, 2012.

${ }^{53}$ Cfr. I.C. IBÁN, en Derecho Eclesiástico, Madrid 1997, p. 92.

${ }^{54}$ Cfr. J. Giménez MARTínez de CARVAJAL, Naturaleza jurídica, valor y estructura de los Acuerdos en «Los Acuerdos entre la Santa Sede y el Estado español (Veinte años de vigencia)», Madrid 2001, p. 27.

${ }^{55}$ Cfr. R. Rodríguez Chacón, El factor religioso... cit., pp. 53-61. 
de Canarias planteó hace unos años ante el Tribunal Constitucional dos cuestiones de inconstitucionalidad acerca de algunos artículos del Acuerdo sobre Enseñanza y Asuntos Culturales, que fueron resueltas a favor de su constitucionalidad por el Alto Tribunal. ${ }^{56}$ Los Acuerdos de 1979 son cuatro, y versan, el primero sobre «Asuntos Jurídicos», el segundo sobre «Enseñanza y Asuntos Culturales», el tercero sobre "Asistencia religiosa a las Fuerzas Armadas y servicio militar de clérigos y religiosos» y el cuarto sobre "Asuntos Económicos». Entre los cuatro abarcan los mismos temas contemplados por el Concordato de 1953, por lo que algún autor han calificado a este conjunto de textos como «sistema concordatario». ${ }^{57}$

Estos Acuerdos vienen a establecer, básicamente, el estatuto jurídico de la Iglesia Católica ante el ordenamiento civil, garantizando su libertad institucional frente al Estado y fijando los modos de cooperación entre ambas Potestades en materias de mutuo interés.

Tratándose, en buena medida, de las tradicionalmente denominadas cuestiones mixtas es decir, cuestiones en las que el Estado y la Iglesia tienen intereses muy concretos y definidos, no siempre coincidentes-, era también previsible que pudieran surgir interpretaciones controvertidas de los textos, o dudas a la hora de desarrollar o ejecutar lo pactado. Por ello los cuatro Acuerdos prevén expresamente que las Altas Partes contratantes procederían siempre concertadamente en la resolución de cualquier duda o dificultad en la interpretación o aplicación de lo acordado.

En la práctica hay que constatar que no siempre ha sido así. La Administración del Estado, en ocasiones, tomó iniciativas que suponían una interpretación o aplicación unilateral, como sucedió con la reforma del régimen matrimonial, o la regulación de la situación de la asignatura de Religión dentro del sistema educativo; o cuando retrasó el cumplimiento de algunas de las obligaciones adquiridas ulteriormente, como ocurrió en el caso de la retribución de los profesores de religión no funcionarios.

${ }^{56}$ Vid. Sentencia 80/2007, de 19 de abril de 2007 y Sentencia 38/2007, de 15 de febrero de 2007

${ }^{57}$ Vid. J. Fornés, El nuevo sistema concordatario español, Eunsa, Pamplona 1980. 


\section{El Acuerdo sobre Asuntos Jurídicos}

En este Acuerdo se reconoce en primer lugar, el derecho de la Iglesia a ejercer libremente su misión evangelizadora; el derecho a organizarse según su propias necesidades y, en consecuencia, a crear, modificar y suprimir sus propias circunscripciones, a las que, además, se les reconoce la personalidad jurídica civil en cuanto la tengan canónica y así se comunique al órgano administrativo competente. ${ }^{58}$ También se garantiza a la lglesia la libertad para erigir, aprobar y suprimir institutos de vida consagrada (u órdenes o congregaciones religiosas en la terminología del Acuerdo) y todo tipo de entidades eclesiásticas (asociaciones, cofradías, fundaciones canónicas, etc.), a las que, si ya la tenían, se les reconoce personalidad jurídica civil. Mientras que, para adquirirla en el futuro, se prescribe su inscripción en el correspondiente Registro del Estado. ${ }^{59}$

Por otro lado, se reconoce y garantiza la inviolabilidad de los lugares de culto y los archivos eclesiásticos, la libertad de comunicación entre la jerarquía y sus fieles, y entre aquélla y la santa sede. se regula también la eficacia jurídica civil tanto del matrimonio canónico como de las sentencias de nulidad de los tribunales eclesiásticos y las declaraciones de rato y no consumado.

Además se reconoce a la Iglesia el derecho a prestar asistencia religiosa a los ciudadanos internados en centros penitenciarios, sanitarios o asistenciales públicos, aunque la regulación concreta de esta asistencia se remite a futuros Convenios. ${ }^{60}$

\footnotetext{
${ }^{58}$ Es decir, la actual Dirección General de Cooperación Jurídica Internacional y Relaciones con las Confesiones del Ministerio de Justicia.

${ }^{59}$ El Registro de Entidades Religiosas, ubicado en el Ministerio de Justicia, y creado por la Ley Orgánica de Libertad Religiosa, de 5 de julio de 1980. Sobre la inscripción de estas entidades vid. J. MANTECón, El Registro de Entidades Religiosas del Ministerio de Justicia y la inscripción de las denominadas entidades menores, en «Revista General de Legislación y Jurisprudencia» (Núm. 1 de 2002) , pp. 29-56.

${ }^{60} \mathrm{Cfr}$. los Acuerdos sobre Asistencia Religiosa Católica en Establecimientos Penitenciarios, de 24 de noviembre de 1993 (BOE de 14 de diciembre); en Centros Hospitalarios Públicos, de 24 de julio de 1985 (BOE de 21 de diciembre), y el Convenio sobre Asistencia Religiosa Católica en los Centros Hospitalarios del Instituto
} 


\section{El Acuerdo sobre Asistencia Religiosa a las Fuerzas Armadas y Servicio Militar de Clérigos y Religiosos}

En este Acuerdo se garantiza la asistencia religiosa a los miembros católicos de las Fuerzas Armadas y a sus familias mediante una institución eclesiástica, pero históricamente vinculada a las Fuerzas Armadas españolas, como es el Vicariato Castrense (denominado ahora Arzobispado Castrense). Los capellanes castrenses estaban integrados en la estructura orgánica de los ejércitos a través de los denominados Cuerpos Eclesiásticos, de modo que formaban parte del Ejército y ostentaban la graduación correspondiente (por ejemplo, el Vicario General castrense tenía grado de general). Se trataba de una solución típica de los Estados confesionales, y por tanto poco adecuada a la nueva situación de aconfesionalidad estatal. Por eso, dichos Cuerpos fueron declarados a extinguir (respetando los derechos adquiridos), siendo sustituidos por un "Servicio de Asistencia Religiosa» (SARFA), basado en un régimen de contratación (y no de integración orgánica), más acorde con las nuevas exigencias constitucionales. ${ }^{61}$

El Acuerdo contemplaba también el modo en que debían realizar el servicio militar los sacerdotes y religiosos, pero en este punto ha dejado de tener vigencia, ya que el servicio militar obligatorio ha desaparecido en España desde el 31 de diciembre de $2001 .{ }^{62}$

Nacional de la Salud, de 23 de abril de 1986 (publicado en el Boletín Oficial de la Conferencia Episcopal, 10, abril-junio 1986).

${ }^{61}$ Cfr. Disposición Derogatoria 2a y Disposición Final 7ạ de la Ley 17/1989, de 19 de julio, reguladora del Régimen del Personal Militar Profesional (BOE de 22 de julio), y el Real Decreto 1145/1990, de 7 de septiembre, por el que se crea dicho Servicio (BOE de 21 de septiembre).

62 Cfr. Real Decreto 247/2001, de 9 de marzo, por el que se adelanta la suspensión de la prestación del servicio militar al 31 de diciembre de 2001 (BOE de 10 de marzo). 


\section{El Acuerdo sobre Enseñanza y Asuntos Culturales}

Este Acuerdo, entre otros temas, viene a arbitrar para los católicos el modo de satisfacer el derecho constitucional, reconocido en el artículo 27.3, a recibir enseñanza religiosa de acuerdo con las propias convicciones. La solución concordada consiste en que el Estado se compromete a que la asignatura de religión católica sea de oferta obligatoria por parte de los Centros educativos (como forma de garantizar el derecho), aunque sea optativa para los alumnos en virtud del derecho de libertad religiosa. ${ }^{63}$ La materia de religión se equipara a las materias fundamentales, por lo que los profesores que la imparten forman parte del Claustro de profesores de los centros educativos.

Para asegurar la no injerencia del Estado en cuestiones estrictamente confesionales, los profesores son designados por la Autoridad académica entre aquéllos que propone el Ordinario del lugar. Por la misma razón, también corresponde a la jerarquía católica señalar los contenidos de esa enseñanza, así como aprobar los libros de texto. El régimen económico laboral de estos profesores se ha concretado a través de diversos Convenios con la Conferencia Episcopal (debidamente autorizada por la Santa Sede, al tratarse del desarrollo y ejecución de lo pactado en un tratado internacional del que es parte la Sede Apostólica). ${ }^{64}$

Para quienes no optaran por la enseñanza de la religión católica, la Administración dispuso una materia alternativa, cuyo contenido y régimen han ido cambiando a lo largo de los

63 Según los datos ofrecidos por la Conferencia Episcopal en el curso escolar 2015/2016, un 63\%, de los alumnos españoles eligió la asignatura optativa de Religión católica, con un número total de 3.666.816 alumnos inscritos. En la escuela pública, los inscritos fueron el 53\%; en las escuelas católicas el 97\%; y en las privadas el $60 \%$

${ }^{64} \mathrm{Cfr}$. Convenio sobre el régimen económico-laboral de los profesores de religión católica no funcionarios en los Centros públicos de Educación Infantil, Primaria, y Secundaria, de 26 de febrero de 1999 (BOE de 20 de abril). La Ley Orgánica 10/2002, de 23 de diciembre, de Calidad de la Educación (BOE de 24 de diciembre de 2002), establece en su Disposición Adicional 2a un régimen general para los profesores de religión no funcionarios de las Confesiones con Acuerdo. 
años. Si en un primer momento se trató de una verdadera asignatura alternativa -ética no confesional-, posteriormente llegó a carecer de un contenido docente objetivo para transformarse en una serie de actividades para-escolares -juegos, pasatiempos, etc.-, o de mero estudio vigilado.

La regulación de la alternativa a la religión ha sido materia de fricciones que, en ocasiones acabaron en los Tribunales, ${ }^{65}$ entre la Administración Educativa, la Conferencia Episcopal y diversos colectivos de padres y profesores, por considerar que se discriminaba a la asignatura de religión católica y se incumplía el Acuerdo. ${ }^{66}$ La Ley Orgánica sobre la Calidad de la Educación de 2002, así como los Reales Decretos que la desarrollaron parecía haber encontrado una fórmula que daba satisfacción a la Iglesia ${ }^{67}$ (y, así mismo, a las demás Confesiones). ${ }^{68}$ Sin embargo, esta Ley no llegó a entrar en vigor porque el nuevo gobierno socialista promulgó la Ley Orgánica de Educación de 2006,69 que sustituyó a aquélla, por la que la asignatura volvía a la situación anterior. La nueva Ley Orgánica de Mejora de la Calidad Educativa (LOMCE), de 2013 mantiene básicamente el estatuto de la asignatura ${ }^{70}$, pero

65 Vid. C. DE DIEGo-Lora, Los Acuerdos en las sentencias de los Tribunales españoles, en «Los Acuerdos entre...», cit., pp. 57-87.

${ }^{66}$ Para conocer el punto de vista de la Iglesia en esta polémica vid. COMISIÓN EPISCOPAL DE ENSEÑANZA Y CATEQUESIS, Documentación jurídica, académica, y pastoral sobre la Enseñanza Religiosa Escolar y sus Profesores (1990-2000), Madrid, 2001; R.M. DE LA CIERVA, Enseñanza de la Religión católica en centros públicos, en «Los Acuerdos entre...» cit., pp. 147-180.

67 Vid. M.E. OLMOS, Sociedad, cultura y religión: nueva área de conocimiento propuesta por la Ley de Calidad de la Educación, en «Revista General de Derecho Canónico y Derecho Eclesiástico del Estado», 1 (2003). ${ }^{68}$ Cfr. Disposición Adicional 2a de la Ley Orgánica de Calidad de la Educación, cit.; Reales Decretos 830, 831 y 832/2003, de 27 de junio, por los que se establecen, respectivamente, las enseñanzas comunes de la Educación Primaria (BOE de 2 de junio), de la Educación Secundaria Obligatoria (BOE de 3 de julio) y del Bachillerato (BOE de 4 de julio).

${ }^{69}$ Ley Orgánica 2/2006, de 3 de mayo, de Educación (BOE de 4 de mayo).

70 Vid. I. BRIONES, Análisis de la Ley Orgánica de Mejora de la Calidad de la Educación y su repercusión sobre la libertad de conciencia y la educación en familia, en VV.AA. «Educación en familia», Madrid, 2014. 
incluye la existencia de una asignatura alternativa para los alumnos que no eligen religión. ${ }^{71}$

\section{El Acuerdo sobre Asuntos Económicos}

Tradicionalmente la Iglesia en España era subvencionada con cargo a los presupuestos generales del Estado en concepto de reparación por las desamortizaciones del siglo XIX, y como contribución del Estado a las actividades benéficas y asistenciales realizadas por la Iglesia en bien de la Nación.

Como se indica en el preámbulo de este Acuerdo, "el Estado no puede ni desconocer ni prolongar indefinidamente obligaciones jurídicas contraídas en el pasado»; y por otra parte, los nuevos principios constitucionales exigen una profunda modificación de lo acordado con anterioridad en esta materia.

Hasta que se logre la deseada autofinanciación a la que explícitamente declara aspirar la Iglesia, el Estado se compromete a ayudar a su sostenimiento de diversas maneras, en tres fases sucesivas. En primer lugar se establecía una fase mínima de tres años, en la que el Estado seguiría consignando en sus Presupuestos Generales una cantidad global destinada al sostenimiento de la Iglesia. En una segunda fase se preveía la puesta en vigor un sistema mixto, en el que, por un lado, la Iglesia contaría con una cantidad recaudada en base a la indicación de los contribuyentes, que podrían destinar libremente a la Iglesia un 0’5 \% de su Impuesto sobre la Renta de las Personas Físicas (sistema que se ha denominado asignación tributaria); y por otro, el Estado complementaría por vía presupuestaria la cantidad correspondiente, hasta alcanzar un total igual al de la última dotación presupuestaria. Tras dicho período, la Iglesia sólo contaría con lo recaudado a través de la asignación tributaria, sistema para el que no se establecía ningún término temporal. En la práctica, el período transitorio mixto se prolongó hasta el año 2006, en que se negoció un cambio del

\footnotetext{
${ }^{71}$ Ley Orgánica 8/2013, de 9 de diciembre (BOE de 10 de diciembre).
} 
sistema, mediante un canje de Notas, que aumentó la cuota del IRPF hasta el $7 \%$, y suprimió el complemento de la dotación presupuestaria, que resulta incómodo para ambas Partes y al límite de la inconstitucionalidad.

Por otra parte, el Estado coopera económicamente de manera indirecta con la Iglesia, mediante exenciones fiscales y tributarias, en atención a los fines no lucrativos y sociales (normalmente educativos, benéficos o asistenciales) de la Iglesia y de sus entidades.

\section{A modo de conclusión: El futuro de los Acuerdos}

La valoración global de los Acuerdos por ambas Partes parece ser positiva, con independencia de que, en algún punto concreto y en determinados momentos, hayan podido producirse divergencias y problemas en su interpretación y aplicación. Ciertamente, lo pactado responde a las aspiraciones de la Iglesia, y en este sentido puede afirmarse que es una concreta y correcta manifestación del explícito mandato constitucional de cooperación con la Iglesia Católica, contenido en el artículo 16, por más que algunos sectores políticos sean reacios a comprender y admitir las exigencias concretas de este precepto de nuestra Constitución.

La Iglesia, de otro lado, frente a quienes consideran que los Acuerdos deberían revisarse, ha manifestado explícitamente su satisfacción con los textos actuales. Es decir, no pretende revisarlos o cambiarlos, sin que por ello haya habido discretos ensayos académicos sobre su posible revisión ${ }^{72}$. A lo que realmente aspira es a que se cumplan íntegramente, en especial el Acuerdo sobre Enseñanza y Asuntos Culturales.

Por el lado estatal, los representantes políticos de los partidos de izquierda se muestran más partidarios de denunciar los Acuerdos que de reformarlos, y así lo manifestaron en las

72 Vid. S. Bueno Salinas, Los Acuerdos entre la Santa Sede y el Estado español a los 25 años de su vigencia, «Revista General de Derecho Canónico y Derecho Eclesiástico del Estado», 8 (2005), pp. 1-19. 
campañas electorales previas a las dos últimas elecciones generales ${ }^{73}$. No obstante, la experiencia histórica nos muestra que ha sido, precisamente durante gobiernos socialistas cuando han tenido lugar algunas mejoras en el régimen de los Acuerdos. Por ejemplo, en el año 2006, mediante una Nota Verbal, tuvo lugar el aumento del porcentaje del IRPF destinado a financiar a la Iglesia Católica, que pasó del 0,5\% al 0,7\% ${ }^{74}$.

El problema de su posible denuncia podría plantearse si, efectivamente, surgiera un gobierno de izquierdas entre el Partido Socialista y Podemos, pero sería más dudoso con un gobierno socialista y, absolutamente descartable son un gobierno de centro-derecha del Partido Popular o mixto del Partido Popular con Ciudadanos.

En todo caso, los textos de los Acuerdos se han demostrado a lo largo de los años y hasta el presente como satisfactorios. Personalmente les auguro todavía años de vigencia, a no ser que ocurriera un cataclismo político en España. Y no sería la menor razón para su continuidad la existencia de los tres Acuerdos de cooperación con las federaciones protestante (FEREDE), judía (FCJE) e islámica (CIE). Si se denunciaran los Acuerdos con la Santa Sede, lo lógico sería denunciar también los firmados con las otras Confesiones y no creo que el Gobierno se preste a derogar los Acuerdos firmados con las minorías porque supondría un paso atrás en el desarrollo de la libertad religiosa de estas Confesiones. En efecto, ¿̇aceptarían las Confesiones minoritarias -y la opinión pública con ellas- que se diera marcha atrás en materias por las que tanto han luchado y durante tanto tiempo? No sería fácil de justificar ante la opinión internacional, que lo vería como un retroceso en materia de liber-

${ }^{73}$ Cfr. J. MANTECón, España: ¿YY si se denunciaran los Acuerdos con la Santa Sede?, «Revista General de Derecho Canónico y Derecho Eclesiástico del Estado» 29 (2015), p.2; R. BENEYTO BERENGUER, El futuro de los Acuerdos entre el Estado español y la Santa Sede (según los programas de los partidos políticos a las elecciones generales del 2015), «Revista General...» cit., 41 (2016), pp. 1-60.

${ }^{74} \mathrm{Cfr}$. http://www.conferenciaepiscopal.es/intercambio-de-notas-entre-la-nunciatura-apostolica-en-espana-y-el-ministerio-de-asuntos-exteriores-y-cooperacion-referidas-a-los-acuerdos-sobre-asignacion-tributaria-a-favor-de-la-iglesia-catolica/ (visita el 4 de septiembre de 2016). 
ISSN 0719-7160

tad religiosa. Y si no se denunciaran se provocaría una clara ruptura del principio constitucional de igualdad, pues estas Confesiones mantendrían, por ejemplo, un trato fiscal favorable del que se habría privado a la Iglesia Católica. ${ }^{75}$

No obstante, y como se ha indicado supra, no parece existir voluntad política de modificar estos Acuerdos de cooperación. Cabe, en todo caso, como ha mostrado la praxis, la posibilidad de su desarrollo mediante medidas unilaterales del Estado -legislativas o administrativas-, e incluso mediante convenios.

${ }^{75}$ Cfr. J. MANTECón, España: ¿YY si se denunciaran... cit., p. 26. 